\section{BIOCHEMICAL STUDIES ON \\ 2-DEOXY-SCYLLO-INOSOSE, AN EARLY INTERMEDIATE IN THE BIOSYNTHESIS OF 2-DEOXYSTREPTAMINE \\ IV. A CLUE TO THE SIMILARITY OF 2-DEOXY-SCYLLO-INOSOSE SYNTHASE TO DEHYDROQUINATE SYNTHASE}

Sir:

2-Deoxystreptamine (1), is a common aminocyclitol aglycon in a major group of clinically important aminoglycoside antibiotics. The crucial step in the biosynthesis of $\mathbf{1}$ is the formation of the precursor, 2-deoxy-scyllo-inosose (2), from D-glucose (3) via the intramolecular C-C bond formation between $\mathrm{C}-1$ and $\mathrm{C}-6^{1,2)}$ The transformation of 3 into 2 was proposed by us to involve a multi-step mechanism as shown in Scheme 1, the chemistry of which was suggested to be similar to the dehydroquinate synthase in the shikimate pathway, ${ }^{3,4}$ ) and an enzyme responsible of the intramolecular cyclization was named "2-deoxy-scyllo-inosose synthase" 5 8) AKHTAR then reported that the C-4 hydrogen of $\mathbf{3}$ was lost during the biosynthesis of $\mathbf{1}$ in the whole cells of Streptomyces fradiae (producing neomycins) and suggested involvement of oxidoreduction at $\mathrm{C}-4$ of the substrate. ${ }^{7,8)}$ However, nothing has so far been clarified as to whether a single enzyme is involved or certain dissociable enzymes cooperate to form 2 . This communication is an approach to this problem.

Recently, we established a cell-free system from Streptomyces fradiae IFO 13147 cells and successfully observed the production of $\mathbf{2}$ from D-glucose- 6-phosphate (4) in the presence of NAD. ${ }^{9)}$ Using this system, we studied the closer insight into the reaction mechanism of the aforementioned 2-deoxyscyllo-inosose synthase, focusing on the fate of the C-4 hydrogen of 4.

A partially purified enzyme was prepared from the $\left(\mathrm{NH}_{4}\right)_{2} \mathrm{SO}_{4}$ saturation precipitate derived from the $10,000 \times g$ supernatant of the sonicate of S. fradiae cells. ${ }^{9)}$ After dialysis of the precipitate, the enzyme fraction $(20 \mathrm{ml}, 15 \mathrm{mg}$ protein $/ \mathrm{ml})$ was chromatographed over a DEAE-Cellulofine A-800 column (i.d. $1 \mathrm{~cm} \times 15 \mathrm{~cm}$, buffer: $50 \mathrm{mM}$ Tris $-\mathrm{HCl}$, $\mathrm{pH} 7.5$, containing $0.2 \mathrm{~mm}$ of $\mathrm{Co}^{2+}$ and $\mathrm{Mg}^{2+}$ ) with a linear gradient of the $\mathrm{NaCl}(0$ to $0.4 \mathrm{M})$ concentration. The enzyme activity was assayed by the HPLC method described previously. ${ }^{9}$ Appropriate enzyme fractions were collected and used for the isotope-tracer experiments.

D- $\left[4-{ }^{2} \mathrm{H}\right]-3$ (>95\% enriched), which had been synthesized by a literature-cited procedure with slight modifications, ${ }^{10)}$ was chemically converted to $\mathrm{D}-\left[4-^{2} \mathrm{H}\right]-\mathbf{4}$. The enzyme reaction was carried out at $37^{\circ} \mathrm{C}$ for 2 hours with a mixture of the enzyme fraction, $2 \mathrm{~mm}$ of NAD and $1 \mathrm{~mm}$ of either the labeled or the non-labeled substrate. $\mathrm{D}-\left[6,6{ }^{2} \mathrm{H}_{2}\right]-4$ was used as a positive reference. ${ }^{5,6)}$ Production of 2 was quantitated by the aforementioned HPLC analysis. ${ }^{9)}$ The yields usually ranged around $10 \%$. No endogenous or residual 2 was observed in the control experiment. Significant reduction $(\sim 40 \%)$ of the production of 2 was observed in the experiments with the D-[4- $\left.{ }^{2} \mathrm{H}\right]-4$ substrate compared with the non-labeled or D- $\left[6,6-{ }^{2} \mathrm{H}_{2}\right]-4$ substrate (duplicate, data not shown). These observations may be suggestive of the primary kinetic isotope effect

Scheme 1. The proposed mechanism of 2-deoxy-scyllo-inosose (2) synthase reaction in the biosynthesis of 2-deoxystreptamine (1).

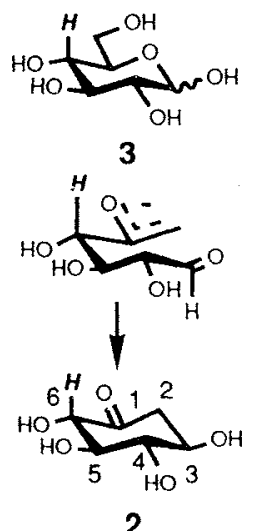

2
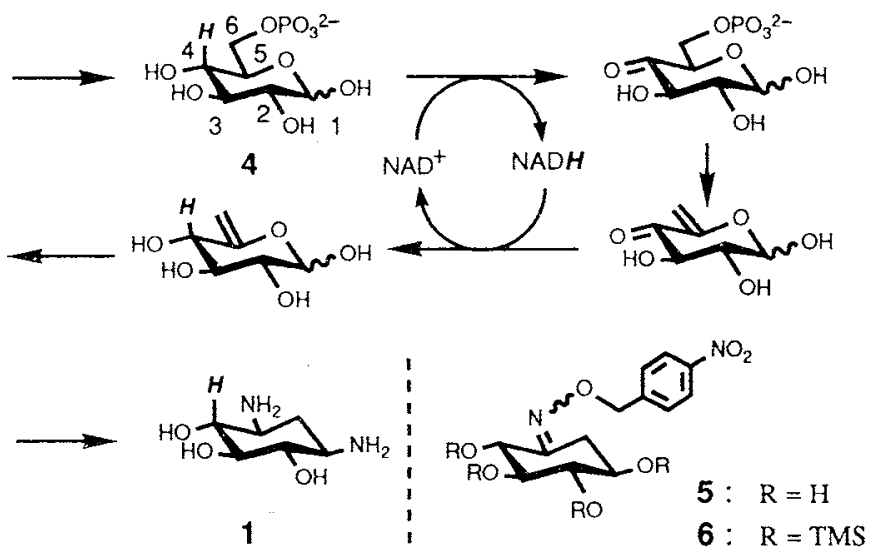
Table 1. Relative intensities of the mass spectra of 6 obtained from the enzyme reaction products and synthetic standard ${ }^{\mathrm{a}}$.

\begin{tabular}{|c|c|c|c|c|c|}
\hline \multirow{2}{*}{ Substrate } & \multicolumn{2}{|c|}{ D-Glucose-6-phosphate } & \multicolumn{2}{|c|}{$\mathrm{D}-\left[4-{ }^{2} \mathrm{H}\right]$ Glucose-6-phosphate } & \multirow{2}{*}{$\begin{array}{c}\text { Chemically synthesized } \\
{\left[6-^{2} \mathrm{H}\right]-2-\text { deoxy- }} \\
\text { scyllo-inosose }\end{array}$} \\
\hline & Run 1 & Run 2 & Run 1 & Run 2 & \\
\hline $\mathrm{m} / \mathrm{z} 599$ & 0 & 0 & 0 & 0 & 0 \\
\hline 600 & 100 & 100 & 56.6 & 57.3 & 0 \\
\hline 601 & 50.3 & 49.0 & 100 & 100 & 100 \\
\hline 602 & 26.3 & 26.4 & 50.6 & 52.4 & 48.3 \\
\hline 603 & 10.5 & 9.1 & 26.3 & 25.3 & 28.9 \\
\hline
\end{tabular}

a Mass spectral scanning was performed in triplicate for each case.

in the oxidoreduction during the 2-deoxy-scylloinosose synthase reaction.

The deuterium enrichment of the enzyme reaction product was determined by mass spectrometry. The $O$-(4-nitrobenzyl)oxime derivatives 5 , prepared from each enzyme reaction, were further separately silylated to the corresponding trimethylsilyl (TMS) ethers 6. Each reaction mixture was diluted, and then subjected to GC-MS (Shimadzu-LKB 9020 DF spectrometer; OV-1, $12 \mathrm{~m}$ ).

The relative signal intensities of the molecular ion region of 6 obtained from each enzyme reaction are shown in Table 1. The non-labeled control showed the $\mathrm{M}^{+}$ion at $m / z 600$, but nothing at $m / z 599$, and only the $\mathrm{M}^{+}$ion $(m / z$ 601) was observed in the spectrum of chemically synthesized $\left[6-{ }^{2} \mathrm{H}\right]-5$ from $\mathrm{D}-\left[4-{ }^{2} \mathrm{H}\right]-3$ as well. ${ }^{11)}$ In contrast, the enzyme reaction product from $\mathrm{D}-\left[4-^{2} \mathrm{H}\right]-4$ showed the ions at $m / z 600$ and $601\left(\mathrm{M}^{+}\right)$, suggesting the formation of both non-labeled and monodeuterated-2. Calculation allowed us to estimate the deuterium content in the product from the $\mathrm{D}-\left[4-{ }^{2} \mathrm{H}\right]-4$ substrate to be $56 \%$. Based upon the previously proposed reaction mechanism, the deuterium of $\mathrm{D}-\left[4-{ }^{2} \mathrm{H}\right]-4$ was expected to be incorporated into $\mathrm{C}-6$ of 2 , which has ultimately been proved as follows.

The location of deuterium in $\mathbf{5}$ obtained from the $\mathrm{D}-\left[4-{ }^{2} \mathrm{H}\right]-4$ substrate was determined unambiguously by ${ }^{2} \mathrm{H}$ NMR spectra as shown in Fig. 1 . The ${ }^{2} \mathrm{H}$ chemical shifts were unequivocally assigned by comparison with the corresponding ${ }^{1} \mathrm{H}$ NMR spectrum of the non-labeled oxime 5 . A positive control, $\left[2,2-{ }^{2} \mathrm{H}_{2}\right]-3$ formed enzymatically from D- $\left[6,6-{ }^{2} \mathrm{H}_{2}\right]-4$, clearly showed the signals at $\delta 2.54$ and 3.81 to be due to the $\mathrm{C}-2$ methylene group $\left({ }^{1} \mathrm{H}\right.$ NMR, $\delta 2.58$ and 3.89). ${ }^{5,6)}$ Most crucial is that the derivative 5 obtained from $\mathrm{D}-\left[4-{ }^{2} \mathrm{H}\right]-\mathbf{4}$ showed a single deuterium signal at $\delta 4.65$, which was attributed to the $\mathrm{C}-6$ position $\left({ }^{1} \mathrm{H}\right.$ NMR, $\left.\delta 4.71\right)$. Thus, the deuterium of the $\mathrm{D}-\left[4{ }^{2} \mathrm{H}\right]-4$ substrate
Fig. 1. ${ }^{2} \mathrm{H} \mathrm{NMR}$ spectra $\left(73.85 \mathrm{MHz}, \mathrm{C}_{5} \mathrm{H}_{5} \mathrm{~N}\right)$ of 5 from enzyme reaction products and ${ }^{1} \mathrm{H}$ NMR spectrum $\left(500 \mathrm{MHz}, \mathrm{C}_{5} \mathrm{D}_{5} \mathrm{~N}\right)$ of the non-labeled standard.

a: $\left({ }^{2} \mathrm{H}\right)$ the product from $\mathrm{D}-\left[6,6{ }^{2} \mathrm{H}_{2}\right]$ glucose- 6 phosphate; $b:\left({ }^{2} \mathrm{H}\right)$ the product from $\mathrm{D}^{-}\left[4^{2} \mathrm{H}\right] \mathrm{glucose}-$ 6-phosphate; $\mathrm{c}:\left({ }^{1} \mathrm{H}\right)$ non-labeled standard. " $\mathrm{S}$ " is the natural abundance signal of deuterium in the solvent.

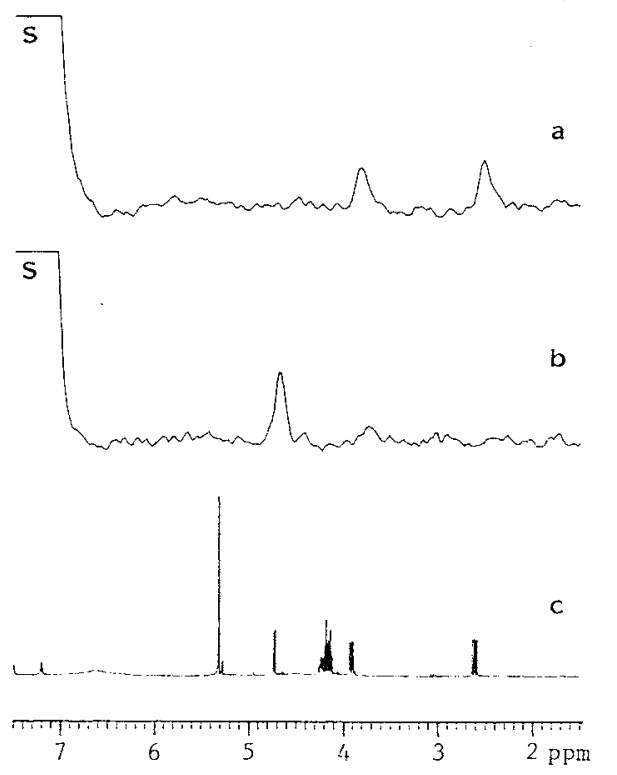

appears to be incorporated into the C-6 position of 2 .

Of significance is that the deuterium at the $\mathrm{C}-4$ position of $\mathrm{D}-\left[4-{ }^{2} \mathrm{H}\right]-4$ is retained in the product during the in vitro reaction of the NAD-assisted 2-deoxy-scyllo-inosose synthase reaction. Thus, the deuterium may be held in the vicinity of the substrate during the NAD-assisted oxidation and reduction. The observed enrichment ratio can be explained as follows. The non-deuterated 2 was probably derived from a minute amount of non-labeled 4 in the $\mathrm{D}-\left[4{ }^{2} \mathrm{H}\right]-4$ specimen. Accordingly, the low transfor- 
mation efficiency $(\sim 10 \%$ chemical yield $)$ and a possible kinetic isotope effect in the oxidoreduction at C-4 seem to effect preferential conversion of the nonlabeled substrate, resulting in significant formation of the non-labeled 2. The aforementioned AKHTAR's in vivo results can be explained similarly ${ }^{7,8)}$

From the present in vitro experiments using a partially purified enzyme, it appears that the formation of 2 from 4 indeed requires NAD and the hydrogen at C-4 of the substrate is retained in the product, thereby suggesting that a series of reactions of 2-deoxy-scyllo-inosose formation may be performed by a single enzyme, "2-deoxy-scylloinosose synthase", with catalytic turn over of the NAD cofactor.

As to the mechanism of dehydroquinate synthase with respect to the 2-deoxy-scyllo-inosose synthase reaction, two features may be emphasized: 1) The C-5 hydrogen (at the $\beta$-position to the phosphate group, synonymous to the C-4 hydrogen of 4) of 3-deoxy-D-arabino-heptulosonic acid 7-phosphate is retained in the cyclization reaction, ${ }^{12)}$ and 2) the NAD requirement is only catalytic and NAD is tightly bound to the enzyme. ${ }^{3)}$ While it is not clear that the 2-deoxy-scyllo-inosose synthase catalyzes only the oxidoreduction and/or cyclization reaction, as has been discussed for the dehydroquinate synthase, ${ }^{4)}$ the present results suggest close similarity of 2-deoxy-scyllo-inosose synthase, functioning in microbial "secondary metabolism", to dehydroquinate synthase in respect to the mechanism. The more datailed comparison must await closer analysis of the former enzyme.

\section{Acknowledgments}

This work was financially supported by Grant-in-Aid for Scientific Research from the Ministry of Education, Science and Culture, and by a Research Grant from the Fujisawa Foundation. Gratitude is also due to Meiji Seika Kaisha Ltd., for large scale preparation of $S$. fradiae IFO 13147 cells.

\section{NoRIaKI YAMAUCHI KATSUMI KAKINUMA*}

Department of Chemistry, Tokyo Institute of Technology, Meguro-ku, Tokyo 152, Japan

\section{References}

1) Rinehart, K. L., Jr. \& R. M. Stroshane: Biosynthesis of aminocyclitol antibiotics. J. Antibiotics 29: $319 \sim 353,1976$

2) Rinehart, K. L., Jr.: Biosynthesis and mutasynthesis of aminocyclitol antibiotics. In Aminocyclitol Antibiotics, ACS Symposium Series No. 125. Eds., K. L. RineharT, Jr. \& T. SuAm, pp. 335 370, American Chemical Society, Washington D.C., 1980

3) Bender, S. L; S. MeHDI \& J, R. KnOwles: Dehydroquinate synthase: The role of divalent metal cations and of nicotinamide adenine dinucleotide in catalysis. Biochemistry 28: 7555 7560, 1989

4) Widlanski, T.; S. L. BendeR \& J. R. KnOWles: Dehydroquinate synthase: A sheep in wolf's clothing? J. Am. Chem. Soc. 111: 2299 2300, 1989

5) Kakinuma, K.; Y. Ogawa, T. Sasaki, H. Seto \& N. ŌTAKE: Stereochemistry of ribostamycin biosynthesis. An application of ${ }^{2} \mathrm{H}$ NMR spectroscopy. J. Am. Chem. Soc. 103: 5614 5616, 1981

6) Kakinuma, K.; Y. Ogawa, T. Sasaki, H. Seto \& N OTAKE: Mechanism and stereochemistry of the biosynthesis of 2-deoxystreptamine and neosamine C. J. Antibiotics 42: 926 933, 1989

7) GODA, S. K. \& M. AKHTAR: The involvement of C-4 of D-glucose in the biosynthesis of the 2deoxystreptamine ring of neomycin. J. Chem. Soc. Chem. Commun. 1987: 12 14, 1987

8) GODA, S. K. \& M. AKhTAR: Neomycin biosynthesis: The incorporation of D-6-deoxy-glucose derivatives and variously labelled glucose into the 2-deoxystreptamine ring. Postulated involvement of 2deoxyinosose synthase in the biosynthesis. J. Antibiotics 45: 984 994, 1992

9) Yamauchi, N. \& K. Kakinuma: Confirmation of in vitro synthesis of 2-deoxy-scyllo-inosose, the earliest intermediate in the biosynthesis of 2-deoxystreptamine, using cell free preparations of Streptomyces fradiae. J. Antibiotics 45: 774 780, 1992

10) Gorin, P. A.: Deuterium isotope effect on shifts of ${ }^{13} \mathrm{C}$ nuclear magnetic resonance signal assignment studies. Can. J. Chem. 52: 458 461, 1974

11) Yamauchi, N. \& K. KaKinuma: Biochemical studies on 2-deoxy-scyllo-inosose, an early intermediate in the biosynthesis of 2-deoxystreptamine. I. Chemical synthesis of 2-deoxy-scyllo-inosose and $\left[2,2-{ }^{2} \mathrm{H}_{2}\right]-2-$ deoxy-scyllo-inosose. J. Antibiotics 45: $756 \sim 766$, 1992

12) Rotenberg, S. L. \& D. B. Sprinson: Isotope effects in 3-dehydroquinate synthase and dehydratase. J. Biol. Chem. 253: 2210 2215, 1978 